\title{
Antibiotics in Pediatric Cataract Surgery: Subconjunctival Versus Intracameral
}

\author{
Rupal H. Trivedi $\cdot$ M. Edward Wilson
}

Published online: 1 October 2013

(c) Springer Science + Business Media New York 2013

\begin{abstract}
Endophthalmitis is an uncommon but potentially devastating intraocular infection that can occur after routine cataract surgery. Prevention is of great importance because of potentially severe consequences of endophthalmitis. Various routes of administration of antibiotics have evolved, including preoperative topical, intraoperative (infusion, intracameral), and postoperative subconjunctival and topical routes. There is growing evidence that intracameral injection of antibiotics at the conclusion of surgery is an effective method of endophthalmitis prophylaxis. The intracameral route of administration is supported by randomized controlled trial data. The evidence supporting subconjunctival antibiotic prophylaxis is retrospective and less conclusive.
\end{abstract}

Keywords Subconjunctival · Intracameral · Cataract . Endophthalmitis

Pediatric cataracts are common and are one of the most treatable causes of lifelong visual impairment in this population. Presently, the only known treatment for a cataract is the surgical removal of the opaque lens. Endophthalmitis is an infrequent but devastating complication of lens-removal surgery. The necessary removal of the posterior capsule in very young patients to prevent reopacification theoretically gives bacteria easier access to the vitreous cavity. The overall incidence of endophthalmitis is reported as

\footnotetext{
R. H. Trivedi ( $\square) \cdot$ M. E. Wilson

Department of Ophthalmology, Miles Center for Pediatric

Ophthalmology, Storm Eye Institute, Medical University

of South Carolina, 167 Ashley Avenue, Charleston,

SC 29425-5536, USA

e-mail: trivedi@musc.edu
}

approximately one in $1,000(0.1 \%)$ in adults [1••]. It is unclear whether children have a higher or lower rate of endophthalmitis. Good et al. [2] reported an incidence of $0.45 \%$ in children. Wheeler et al. [3] surveyed 500 pediatric ophthalmologists and reported an endophthalmitis incidence of $0.07 \%$ following pediatric intraocular surgery for cataracts and congenital glaucoma. The Infant Aphakia Treatment Study reported endophthalmitis in one of 114 eyes $(0.88 \%)$.

Endophthalmitis prevention is better than post de facto cure since the visual morbidity is high even with appropriate treatment. Although prevention is essential for any cataract surgery, eyes with traumatic cataract, reoperation (e.g., secondary intraocular lens), and immediately sequential bilateral cataract surgery may need more aggressive prophylaxis. Practice patterns for prophylaxis of endophthalmitis in children have typically mirrored those applied to adults. In addition to preoperative sterile preparation of the surgical site and proper draping methods, povidone-iodine application prior to cataract surgery remains a universal practice, and is backed by good-quality evidence [4]. In addition, the use of prophylactic antibiotics is almost universal. However, variations have been observed in the route of administration of antibiotics. Although some oral quinolones may achieve significant intraocular levels, many systemically administered antibiotics have not demonstrated good intraocular penetration. Consequently, various routes of administration have evolved, including preoperative topical, intraoperative infusion/intracameral, and postoperative subconjunctival routes (Table 1) [5].

Among the earliest prophylactic techniques to be adopted was postoperative subconjunctival injection of antibiotics. Subconjunctival administration may offer better prophylaxis by behaving as a depot preparation and prolonging the availability of the antibiotic via sustained 
Table 1 Intracameral versus subconjunctival antibiotic prophylaxis for pediatric cataract surgery

\begin{tabular}{lll}
\hline & Intracameral & Subconjunctival \\
\hline $\begin{array}{l}\text { Route } \\
\text { Intraocular } \\
\text { penetration }\end{array}$ & $\begin{array}{l}\text { Intraoperative } \\
\text { Fisadvantage }\end{array}$ & $\begin{array}{l}\text { Immediately postoperative } \\
\text { Can differ significantly }\end{array}$ \\
& $\begin{array}{c}\text { Toxicity if prepared } \\
\text { improperly }\end{array}$ & $\begin{array}{c}\text { Subconjunctival hemorrhage, } \\
\text { toxicity if there is inadvertent } \\
\text { globe penetration into the } \\
\text { vitreous }\end{array}$ \\
$\begin{array}{c}\text { Commonly } \\
\text { used drugs }\end{array}$ & $\begin{array}{c}\text { Cephalosporin, } \\
\text { vancomycin, } \\
\text { moxifloxacin }\end{array}$ & \\
\hline
\end{tabular}

absorption through the ocular coats. The increased duration of intraocular antibiotic levels may impede the establishment of pathogens during the crucial early wound-healing period. Evidence of the benefit of injecting antibiotics into the subconjunctival space at the close of surgery is inconclusive and is associated with risks that include intraocular toxicity with the potential for macular infarction when aminoglycosides are used. A review of the available literature indicates that it may be relevant but cannot be definitely related to clinical outcome (C level evidence) [4]. Ciulla et al. [4] noted that the data supporting the use of subconjunctival antibiotics are somewhat stronger than the data supporting the use of several other prophylactic interventions which also received the clinical recommendation of " $\mathrm{C}$ " (including preoperative lash trimming, preoperative saline irrigation, preoperative topical antibiotics, irrigating solution containing antibiotics, and the use of heparin). This evidence-based study analysis was performed prior to the European Society of Cataract and Refractive Surgeons (ESCRS) study of intracameral antibiotics, which is described below. Efficacy of a subconjunctival injection of antibiotics (DuoCat) has been reported in experimental studies [6].

The most frequent complaint of parents after pediatric cataract surgery and subconjunctival injection relates to subconjunctival hemorrhage at the site of the injection. Despite the excellent technical outcomes, parents are frequently apprehensive because of the appearance of red eyes. For this reason, some surgeons inject the drug superiorly, in an attempt to hide the hemorrhage under the upper eyelid. Conjunctival bleeding can be avoided by using an intracameral route for the drug, as will be discussed below. Intraocular penetration of subconjunctival antibacterials can differ significantly. When a subconjunctival injection is given, the bleb should be created as close to the incision as possible to ensure the highest concentration of intraocular antibiotic.

A direct injection of an antibiotic into the anterior chamber following surgery should theoretically be the most efficient method for delivering therapeutic antibacterial concentrations to the eye at the end of surgery [7••]. The ESCRS multicenter randomized prospective study of the prophylactic effect of intracameral cefuroxime injection at the conclusion of the procedure and/or perioperatively administered levofloxacin eye drops on the incidence of endophthalmitis after phacoemulsification in adult eyes was halted early because of a beneficial effect of intracameral cefuroxime injection [8]. With data from 13,698 patients with complete follow-up records, the investigators found that the odds ratio for developing endophthalmitis was 4.59 [95\% confidence interval (CI) 1.74-12.08; $P=0.002]$ in the group not receiving intracameral cefuroxime injection. Clinicians have argued that there is no evidence that a change to intracameral cefuroxime injection would be a more effective prophylaxis if a relatively low acceptable rate of endophthalmitis is already being achieved with subconjunctival cefuroxime injection. Despite this criticism, more and more physicians are using the intracameral route. Our current anti-infective protocol for pediatric cataract surgery at Storm Eye Institute includes intracameral injection of moxifloxacin $(0.1 \mathrm{~mL}$ of $50 \%$ dilution, $250 \mu \mathrm{g}$ ). Each milliliter of Vigamox solution contains $5 \mathrm{mg}(5,000 \mu \mathrm{g})$. We no longer administer subconjunctival antibiotics at the conclusion of surgery.

The ESCRS study did not compare the intracameral route with the subconjunctival delivery of antibiotics. The very high concentration of antibiotic achieved from intracameral injection is reduced $1.5-2 \mathrm{~h}$ after surgery; therefore, intracameral antibiotics alone offer no protection if there was bacterial ingress after the completion of the surgery, as might be expected in the case of a wound leak following surgery $[7 \bullet \bullet]$. Comparison of intracameral injection and subconjunctival injection of cefuroxime as a prophylactic agent in cataract surgery has been reported in a retrospective study in an adult population [9]. The study included 36,743 phacoemulsification cataract procedures. The mean rate of presumed infectious endophthalmitis was 0.95 per 1,000 cases. The incidence of endophthalmitis was higher in the group receiving subconjunctival injection of cefuroxime than in the group receiving intracameral injection of cefuroxime; the difference was statistically significant, with an odds ratio of 3.01 (95\% CI 1.37-6.63) [9]. Tan et al. [10॰•] reported the overall incidence of postoperative endophthalmitis in 50,177 subjects was $0.042 \%$. Between July 1999 and June 2006, the medications given at the end of cataract surgery were subconjunctival injections of cefazolin $(1 \mathrm{mg}$ in $0.1 \mathrm{~mL})$, gentamicin $(0.2 \mathrm{~mL}$ of $80 \mathrm{mg}$ in $2 \mathrm{~mL})$, and dexamethasone $(0.4 \mathrm{mg}$ in $0.1 \mathrm{~mL})$. During these 7 years, when all immediate postoperative antibiotic agents were administered by subconjunctival injection, there were 19 cases in 29,539 surgical procedures $(0.064 \%, 64.3$ per 100,000$)$. 
From July 2006 forward, cefazolin was given as an intracameral injection $(1.0 \mathrm{mg}$ in $0.1 \mathrm{~mL})$ instead and gentamicin and dexamethasone continued to be administered subconjunctivally. After the introduction of intracameral injection of cefazolin, there were two cases of endophthalmitis in 20,638 subjects $(0.010 \%, 9.7$ per 100,000$)$. The reduction in the incidence of endophthalmitis after the use of intracameral injection of cefazolin was statistically significant (univariate odds ratio, 6.64; $95 \%$ CI 1.55-28.5; $P=0.003$ ) $[10 \bullet \bullet]$. Both patients with endophthalmitis who presented after the use of intracameral injection of cefazolin had very poor visual outcomes; the eye in one patient was eviscerated, and the other patient had a visual outcome of light perception only. It has been suggested that although intracameral antibiotic agents may reduce the overall rates of endophthalmitis, the remaining organisms that cause infection may be more virulent and result in a poorer outcome.

Although the intracameral delivery of antibacterials has been shown to be effective in preventing endophthalmitis, the optimal choice of drugs has yet to be determined. Commonly used doses for intracameral use in adult eyes undergoing cataract surgery are are listed in Table 2 . Intracameral injection of cefuroxime is widely used in Europe but is used less often in the USA, where some physicians have expressed concerns regarding risks of contamination or dilution errors during the compounding process (preparing drugs for ocular use) that could cause ocular toxicity. These concerns include risks associated with preparing the solution, including dilution errors, bacterial contamination, or toxic anterior segment syndrome. To overcome these concerns, intracameral use of moxifloxacin has been suggested as an alternative. Several recent reports have focused on the use of intracamerally injected preservative-free moxifloxacin since it does not require a detailed dilution when taken from the commercially available topical solution and used intracamerally. Of the late-generation topical fluoroquinolones, moxifloxacin has been studied most, in part because one of its commercially available topical formulations (Vigamox) is already preservative-free and seems to have no obvious toxic effects if it is injected into the anterior chamber [11]. An intracameral injection of $250 \mu \mathrm{g}$ of moxifloxacin produces an aqueous humor concentration of $710-1,250 \mu \mathrm{g} /$ $\mathrm{mL}(250 \mu \mathrm{g}, 0.2-0.35 \mathrm{~mL})$ with less systemic effects and less risk of antibiotic resistance compared with other routes of administration [12]. Since aqueous humor is formed at a rate of $2-3 \mu \mathrm{L} / \mathrm{min}$, the high aqueous humor concentration should be maintained for $1.5-2 \mathrm{~h}$ after surgery [11, 13-15].

There is a concern that late-generation fluoroquinolones may be less effective in preventing endophthalmitis caused by methicillin-resistant Staphylococcus aureus [11]. Although intracameral injection of cefuroxime has proven
Table 2 Intracameral dose

Cefuroxime: $1 \mathrm{mg}$ in $0.1 \mathrm{~mL}$ saline $(0.9 \%)$

Vancomycin: $1 \mathrm{mg}$ of vancomycin in $0.1 \mathrm{~mL}$ of balanced salt solution

Moxifloxacin: $250 \mu \mathrm{g}$ of moxifloxacine (Vigamox brand has no preservative) given as $0.05 \mathrm{~mL}$ of undiluted [19] or $0.1 \mathrm{~mL}$ if diluted 1 to 1 with balanced salt solution. Prepare solution from a newly opened bottle using a tuberculin syringe

to be efficacious in preventing postoperative endophthalmitis overall, its activity against enterococci is poor. Several of the endophthalmitis cases in eyes receiving intracameral injection of cefuroxime were caused by enterococci, and these had a poor visual outcome [7••]. Cefuroxime concentrations higher than $2.75 \mathrm{mg} / \mathrm{mL}$ and vancomycin concentrations higher than $5.0 \mathrm{mg} / \mathrm{mL}$ have been shown to cause a significant reduction in corneal endothelial cell viability [16]. This study reported dosedependent toxicity of cefuroxime and vancomycin toward human corneal endothelial cells in vitro with a narrow range of safety and concluded that although the clinically used concentrations seem to be safe, slightly higher concentrations might induce irreversible cell death and thus should be avoided [16].

Vancomycin is also commonly used as an intracameral antibiotic. However, as vancomycin is commonly used for the treatment of endophthalmitis, the US Centers for Disease Control and Prevention guidelines caution against the addition of vancomycin to infusion fluids to avoid resistance to the organisms. Some authors argue that intracameral use in ophthalmology carries a very low risk of producing resistance [17]. Another concern about using vancomycin is an increased incidence of cystoid macular edema after cataract surgery with intraocular vancomycin [18].

\section{Summary}

Given the seriousness of endophthalmitis as an adverse event, the optimal choice and mode of delivery of perioperative antibiotic agents remain important issues. Evidence is stronger that intracameral antibiotics reduce endophthalmitis compared with subconjunctival antibiotics. Surgeons must weigh that evidence against the potential for toxicity if intracameral drugs are not properly compounded. Given the absence of clear evidence about the benefit of many prophylactic measures, it is up to the ophthalmologist to decide on the use of any particular strategy in addition to povidone-iodine in the perioperative period. A review of the literature shows the data supporting the use of intracameral antibiotics to be stronger than the data supporting the use of subconjunctival antibiotics. 
Acknowledgments This work was supported in part by an unrestricted grant to Medical University of South Carolina, Storm Eye Institute from Research to Prevent Blindness (New York, NY, USA).

Disclosure The authors have no financial or proprietary interest in any product mentioned herein. Rupal $\mathrm{H}$. Trivedi and $\mathrm{M}$ Edward Wilson declare no conflict of interest.

Human and Animal Rights and Informed Consent This article does not contain any studies with human or animal subjects performed by any of the authors.

\section{References}

Papers of particular interest, published recently, have been highlighted as:

-• Of major importance

1. •- Packer M, Chang DF, Dewey SH, et al. Prevention, diagnosis, and management of acute postoperative bacterial endophthalmitis. J Cataract Refract Surg. 2011;37:1699-714. This article reviewing the literature on infection after adult cataract surgery summarizes epidemiology, etiology, and pathogenesis and describes the role of antibiotic prophylaxis in prevention of endophthalmitis.

2. Good WV, Hing S, Irvine AR, et al. Postoperative endophthalmitis in children following cataract surgery. J Pediatr Ophthalmol Strabismus. 1990;27:283-5.

3. Wheeler DT, Stager DR, Weakley DR Jr. Endophthalmitis following pediatric intraocular surgery for congenital cataracts and congenital glaucoma. J Pediatr Ophthalmol Strabismus. 1992;29:139-41.

4. Ciulla TA, Starr MB, Masket S. Bacterial endophthalmitis prophylaxis for cataract surgery: an evidence-based update. Ophthalmology. 2002;109:13-24.

5. Wejde G, Montan P, Lundstrom M, et al. Endophthalmitis following cataract surgery in Sweden: national prospective survey 1999-2001. Acta Ophthalmol Scand. 2005;83:7-10.

6. Cardillo JA, Paganelli F, Melo LA Jr, et al. Subconjunctival delivery of antibiotics in a controlled-release system: a novel anti-infective prophylaxis approach for cataract surgery. Arch Ophthalmol. 2010;128:81-7.

7. - Fintelmann RE, Naseri A. Prophylaxis of postoperative endophthalmitis following cataract surgery: current status and future directions. Drugs. 2010;70:1395-409. This article describe the current status and future directions for prophylaxis of postoperative endophthalmitis following cataract surgery.
8. Barry P, Seal DV, Gettinby G, et al. ESCRS study of prophylaxis of postoperative endophthalmitis after cataract surgery: preliminary report of principal results from a European multicenter study. J Cataract Refract Surg. 2006;32:407-10.

9. Yu-Wai-Man P, Morgan SJ, Hildreth AJ, et al. Efficacy of intracameral and subconjunctival cefuroxime in preventing endophthalmitis after cataract surgery. J Cataract Refract Surg. 2008;34:447-51.

10. •• Tan CS, Wong HK, Yang FP. Epidemiology of postoperative endophthalmitis in an Asian population: 11-year incidence and effect of intracameral antibiotic agents. J Cataract Refract Surg. 2012;38:425-30. This article describe the incidence of postoperative endophthalmitis after cataract surgery in large series $(n=50,177)$. The authors compared the endophthalmitis rates before and after the use of intracameral antibiotic agents. The authors concluded that there was a significant reduction in the rate of postoperative endophthalmitis with the use of intracameral injection of cefazolin.

11. Arbisser LB. Safety of intracameral moxifloxacin for prophylaxis of endophthalmitis after cataract surgery. J Cataract Refract Surg. 2008;34:1114-20.

12. McCulley JP, Caudle D, Aronowicz JD, et al. Fourth-generation fluoroquinolone penetration into the aqueous humor in humans. Ophthalmology. 2006;113:955-9.

13. Espiritu CR, Caparas VL, Bolinao JG. Safety of prophylactic intracameral moxifloxacin $0.5 \%$ ophthalmic solution in cataract surgery patients. J Cataract Refract Surg. 2007;33:63-8.

14. O'Brien TP, Arshinoff SA, Mah FS. Perspectives on antibiotics for postoperative endophthalmitis prophylaxis: potential role of moxifloxacin. J Cataract Refract Surg. 2007;33:1790-800.

15. Kowalski RP, Romanowski EG, Mah FS, et al. Intracameral Vigamox (moxifloxacin $0.5 \%$ ) is non-toxic and effective in preventing endophthalmitis in a rabbit model. Am J Ophthalmol. 2005;140:497-504.

16. Yoeruek E, Spitzer MS, Saygili O, et al. Comparison of in vitro safety profiles of vancomycin and cefuroxime on human corneal endothelial cells for intracameral use. J Cataract Refract Surg. 2008;34:2139-45.

17. Shimada $\mathrm{H}$, Arai $\mathrm{S}$, Nakashizuka $\mathrm{H}$, et al. Reduction of anterior chamber contamination rate after cataract surgery by intraoperative surface irrigation with $0.25 \%$ povidone-iodine. Am J Ophthalmol. 2011;151(11-17):e11.

18. Axer-Siegel R, Stiebel-Kalish H, Rosenblatt I, et al. Cystoid macular edema after cataract surgery with intraocular vancomycin. Ophthalmology. 1999;106:1660-4.

19. Lane SS, Osher RH, Masket S, et al. Evaluation of the safety of prophylactic intracameral moxifloxacin in cataract surgery. J Cataract Refract Surg. 2008;34:1451-9. 